Guest Editorial

\title{
2004 RACI One-day Natural Products Group Symposium
}

\section{Peter Karuso}

Department of Chemistry \& Biomolecular Sciences, Macquarie University, Sydney Australia. Tel. (+612)-9850-8290, Fax (+612) 9850-8313, e-mail peter.karuso@mq.edu.au

Received: 28 July 2005 / Published: 31 October 2005

This special issue of Molecules is dedicated to the Royal Australian Chemical Institute's Natural Products group. The group meets annually, in the first week of October, for a one-day symposium at a venue in the state of New South Wales (NSW), Australia. This year's program was held at Southern Cross University (SCU) in Lismore and attracted a large audience from Queensland, as well as NSW, because of Lismore's proximity to the Queensland border.

The most recent program can be found on the web at http://www.chem.mq.edu.au/npg. This collection of seven papers form the proceedings of the 2004 one-day symposia and I would like to thank the authors for their patience and our sponsors Davies Collison Cave, Biosignal, Agilent Technologies, Medos and of course the Royal Australian Chemical Institute (RACI) for their generous support.

Natural products chemistry has a long history in Australia. In fact, the first chemistry department in the country, at the University of Sydney, was founded on natural products chemistry with such great names as H. G. Smith, Sir Robert Robinson, Ernest Ritchie, W. C. Taylor and Rod Richard, to name just a few. Australia's unique flora and fauna has assured more or less continuous interest in natural products chemistry in this country, both terrestrially and (more recently) in the marine environment. However, interest in natural products and natural product chemistry has surged in the last year or two and we all hope that this trend continues, spurred on by the new Biotech boom that is focused on the pharmaceutical industry and the quest for new products for human health.

The scientific program reflected the current state of natural products chemistry in Australia and the first paper in the special issue, by Ian Southwell, set the scene by outlining the history of natural products research in the Department of Primary Industries over the past 25 years. An historic perspective also opened the Symposium, with a lecture from Peter Waterman, who also opened the 1999 RACI Natural Products Symposium [1]. At that time, Southern Cross University lured Peter from the UK with the promise of a Centre for Phytochemistry (now Centre of Phytochemistry and 
Pharmacology) and Peter opened the conference this year with a perspective of his research south of the Wallace line during the last five years. A highlight was the story of the aptly named "tasmanone" that exits as a mixture of two isomers related by a 1,3-sigmatropic shift.

Drug discovery has always been a major focus of natural products chemistry and Australia is no exception. Currently there are several drug companies (eg Astra-Zeneca, Novogen, Novartis and Biota) that are actively pursuing drug leads from Australian flora and fauna. We are lucky to have a paper in this issue from Mediherb, a small home-grown bioprospecting company who are interested in the chemical basis for herbal medicines. Marine natural products chemistry began in Australia in the early 1980's with the establishment of the Roche Research Institute for Marine Pharmacology (RRIMP) which met an untimely death in 1984 due to financial difficulties of the parent company. At the time, John Coll at James Cook University was already very active in the natural products of soft corals and other smaller groups existed in Tasmania, Western Australia and Sydney. Today, John's mantle has been taken up by Bruce Bowden and Macquarie University, Wollongong, Flinders and the University of Queensland can be added to the list of Universities involved in marine natural products research. In this issue we have several papers dealing with marine natural products, which range from the classical isolation of sponge natural products to new pigments from marine microorganisms. The second plenary lecture was given by Peter Steinberg from the Centre for Marine Biofouling, who related the tale of the understanding of bacterial quorum sensing discovered in part by the isolation of a potent inhibitor of quorum sensing from the Australian red alga Delisea pulchra. Natural products synthesis also featured in the conference (Kumar, Barrow) but there was a notably large number of papers on natural products from marine microorganisms - a largely untapped source of new compounds.

A way to increase the odds of finding biologically active compounds is to use ethnobotanical data. Three papers in this issue highlight this approach, two by Lehmann et al. from a traditional European perspective (Echinacea chemistry) and one by Jamie and co-workers about the largely untapped Australian Aboriginal pharmacopoeia, a pharmacopoeia that has developed in a megadiverse environment over the past 60,000 years, but one that has developed without written records and that has all but disappeared over the past 200 years.

Peter Waterman predicted that the future holds non-traditional applications for natural products, for example, the study of the environmental effects of natural products. He also warned that the role of the natural products chemist remains as a handmaiden to the other sciences. This rather impoverished view of natural products chemistry denies its historic role in drug discovery, a role that will become more important in the future because alternate strategies such as combinatorial chemistry have been patently unsuccessful in filling the drug companies' product pipelines. Natural products chemists hold the keys as Craig Crew (Yale University) recently told me, but the question remains: the keys to what?

Reactions in nature are biased toward function. This notion sits well with our Darwinian notion of evolution and survival of the fittest, but also helps explain the enormous biochemical expense of storing and maintaining the information required to make natural products (DNA) and the means to make them (enzymes and substrates). It follows then that that every natural product must have a biological receptor and that receptor may not be that different from a human protein [2]. This is supported by recent data on new small molecule chemical entities introduced by the pharma industry from 1981-2002, which revealed that $61 \%$ were natural products or derived from natural product leads 
[3]. This percentage is even higher when considering only anticancer compounds (74\%) or antibacterials (79\%). Clearly, natural products chemists hold the keys to a rich source of drugs and drug leads.

Whether chemists turn to ethnopharmacological data, plants, microorganisms or the marine environment, there is a rich bounty of new chemicals - all of which must be biosynthesized for a purpose. Perhaps it is time for natural products chemist to find out what that purpose is [4]. I hope you enjoy this collection of papers from the 2004 RACI One-day Natural Products Group Symposium.

Peter Karuso, PhD, FRACI, CChem

\section{References}

1. Karuso, P. RACI Natural Products Group Symposium. Molecules 2001, 6, 67-141.

2. Rouhi, A. M. Rediscovering Natural Products. Chem. Eng. News 2003, 81, 77-91.

3. Newman, D. J.; Cragg, G. M.; Snader, K. M. Natural Products as Sources of New Drugs over the Period 1981-2002. J. Nat. Prod. 2003, 66, 1022-1037.

4. Piggott, A. M.; Karuso, P. Quality, not quantity: The role of natural products and chemical proteomics in modern drug discovery. Comb. Chem. High Throughput Screen. 2004, 7, 607-630.

(C) 2005 by MDPI (http:www.mdpi.org). Reproduction is permitted for noncommercial purposes. 